\title{
Fabrication, Characterization, In Vitro Release, and Some Biological Activities of Eucalyptus Essential Oil Loaded Poly (Lactic Acid) Nanofibers
}

\section{Hayfa Argui 1,3*, Salih Can Suner ${ }^{2,5}$, Çağdaş Deniz Periz ${ }^{4}$, Seyhan Ulusoy $^{4}$, Mossadok Ben-Attia ${ }^{3}$, Yalçın Coşkun ${ }^{6}$, Ayhan Oral ${ }^{7}$ and Hechmi Said $^{1}$}

${ }^{1}$ Materials Chemistry Laboratory, Department of Chemistry, Faculty of Sciences of Bizerte, University of Carthage, Tunisia

${ }^{2}$ Department of Chemistry and Chemical Processing, Lapseki Vocational School, Canakkale Onsekiz Mart University, Turkey

${ }^{3}$ Biomonitoring of the Environment Laboratory (LR01/ES14), Faculty of Sciences of Bizerte, University of Carthage, Tunisia

${ }^{4}$ Department of Biology, Faculty of Science, Suleyman Demirel University, Turkey

${ }^{5}$ Canakkale Onsekiz Mart University Application in Science and Technology and Research Laboratory, Turkey

${ }^{6}$ Department of Organic Farming, Lapseki Vocational School, Çanakkale Onsekiz Mart University, Turkey

${ }^{7}$ Department of Chemistry, Faculty of Art and Science, Canakkale Onsekiz Mart University 17100 Çanakkale, Turkey.

*Corresponding Author: Hayfa Argui, Materials Chemistry Laboratory, Department of Chemistry, Faculty of Sciences of Bizerte, University of Carthage, Tunisia.
Received: December 29, 2020

Published: January 28, 2021

(C) All rights are reserved by Hayfa Argui., et al.

\begin{abstract}
The objective of this work was to evaluate antibacterial and antibiofilm activity of Eucalyptus camaldulensis EO-loaded PLA nanofibers. Different concentrations of E. camaldulensis EO (7.5, 10 and 15\%) were incorporated into PLA nanofibers via an electrospinning technique. The nanofibers are characterized by Fourier transform infrared spectroscopy (FT-IR), scanning electron microscopy (SEM) and dynamic mechanical analysis (DMA). Antibacterial activity of essential oil-loaded PLA nanofibers against Staphylococcus aureus, Escherichia coli, Pseudomonas aeruginosa and Enterococcus faecalis were investigated by disc diffusion method. The antibiofilm activity of essential oil-loaded PLA nanofibers was studied against Pseudomonas aeruginosa. The results obtained from the biofilm formation test revealed that PLA essential oil inhibited the Pseudomonas aeruginosa biofilm by $9.3 \%, 12.8 \%$ and $12.6 \%$, respectively. Drug releasing behavior of essential oil-loaded PLA nanofibers was investigated by UV-Visible spectroscopy. According to releasing results, as the amounts of Eucalyptus camaldulensis essential oil in PLA nanofibers increased, the releasing decreased. The essential oil-loaded PLA nanofiber successfully delivered about $160 \mathrm{~h}$.
\end{abstract}

Keywords: Eucalyptus camaldulensis Dehn; Electrospinning; Nanofibers; Drug Delivery; Antibacterial Activity; Antibiofilm Activity

\section{Abbreviations}

EO: Essential Oil; PLA: Poly (Lactic acid); PLA-EUC Nanofibers: $E$. camaldulensis EO Loaded PLA Nanofibers; FT-IR: Fourier Trans- form Infrared Spectrometer; SEM: Scanning Electron Microscopy; DMA: Dynamic Mechanical Analysis. 


\section{Introduction}

The electrospinning method produces nanofibers by electrostatic spinning. It is based on stretching a jet of polymer solution through an electric area to produce synthetic fibres with diameters extending a few nanometres to a few micrometres [1-4], which is arousing the interest of the scientific community [5]. In recent years, the synthetic additives used in many fields (pharmaceutical, cosmetics, food and agriculture) raised many health concerns, associated to their side effects [6]. Hence, natural alternatives such as EOs, which are classified as safe (GRAS) by the United States Food and Drug Administration [7], are needed to replace them. EOs have been the subject of extensive research with the aim of demonstrating biological properties. Today, different antibacterial compounds such as EOs [8] have been incorporated into the PLA matrix to produce new films with antibacterial properties. In addition, research on the development of PLA-based materials having antibacterial properties experienced a great boom in order to extend the shelf-life and increase the quality of food [9]. PLA has received a lot of attention thanks to its renewable resources, its biocompatibility, its biodegradation, good mechanical performance, and the transparency of the [10]. The research cited below reports that natural extracts from bioactive plants could potentially be used as plasticizers for PLA, which reflects the mobility of the polymer chains and minimizes the rate of interactions between the chains, as has also been observed in the case of EO loaded PLA films [8]. Eucalyptus camaldulensis Dehn. is an aromatic plant and medicinal widely used in traditional medicine; their antimicrobial power and chemical compositions have been demonstrated by several studies $[11,12,41-43]$. The main objective of this work is to produce and develop materials based on PLA and to study the applicability of PLA (a biodegradable polymer made from renewable resources such as corn) containing natural agents, as biofilm inhibitor agents. For this, we have chosen the essential oil of E. camaldulensis EO to produce EO-containing PLA nanofibers. First, the mode of inclusion of these active agents in the PLA matrices and their effects on various thermal and mechanical properties were studied. Secondly, a study of the release of active agents was investigated. An evaluation of the antibacterial and anti-biofilm activity of these nanofibers was carried out.

\section{Materials and Methods}

Materials

PLA was purchased from Sigma-Aldrich. Dichloromethane
(DCM), N, N-dimethylformamide (DMF) and tetrahydrofurane (THF) were used as a solvent. The raw material used for the extraction of EO was E. camaldulensis Dehn leaves and twigs, harvested in March 2019 from trees of E. camaldulensis Dehn, located in northern Tunisia (Latitude $37^{\circ} 17^{\prime} 48^{\prime \prime} \mathrm{N} /$ Longitude $10^{\circ} 0^{\prime} 2^{\prime \prime} \mathrm{E}$ ).

\section{Extraction of Eucalyptus camaldulensis EO}

Fresh leaves and twigs of E. camaldulensis Dehn (12 kg) was extracted by steam entrainment method [13] for $3 \mathrm{~h}$ (yield, 0.095\% $(\mathrm{w} / \mathrm{w})$ ). The EO obtained was dried over anhydrous sodium sulphate and stored at $4^{\circ} \mathrm{C}$.

Preparation of the sample

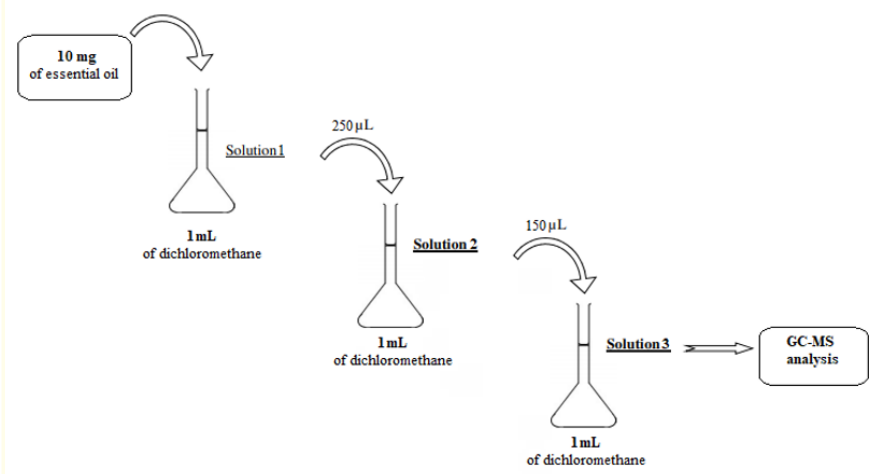

Figure 1: Preparation of EOs extracted from the aerial part of Eucalyptus camaldulensis Dehn.

\section{Chemical composition of E. camaldulensis Dehn. EO}

GC-MS analyses were performed on an Agilent 7890B GC system coupled to a mass selective detector 5977B (Agilent, Santa Clara, CA, USA). HP-5MS capillary column (5\% phenyl-95\% methyl siloxane, $30 \mathrm{~m} \times 0.25 \mathrm{~mm}$, $0.25 \mu \mathrm{m}$ ) was used. Helium was used as a carrier gas (the flow rate was $1 \mathrm{~mL} / \mathrm{min}$ ). One $\mu \mathrm{EO}$ in hexane was injected in split-less mode. The programming of the oven temperature was maintained at $50^{\circ} \mathrm{C}(0 \mathrm{~min})$, and then increased at a rate of $5^{\circ} \mathrm{C} / \mathrm{min}$ up to $260^{\circ} \mathrm{C}(5 \mathrm{~min})$. The source and quadrupole temperatures were fixed at $230^{\circ} \mathrm{C}$ and $150^{\circ} \mathrm{C}$, respectively. Mass range was scanned from 40 to $400 \mathrm{~m} / \mathrm{z}$ with ionizing voltage 70 eV. Data were analyzed using Mass Hunter Workstation Software, Qualitative Analysis Navigator and Qualitative Analysis Workflows (Version B.08.00, Agilent Technologies, Inc. 2016). The identifica- 
tion of the EO components was performed based on chromatographic comparison of the recorded retention time with computed mass-spectrum data libraries (Pal600K).

\section{Antibacterial activities of the E. camaldulensis EO} Spot viability assay

For the assays, the bacterial community was exposed to $(1.55$, 0.775 and 0.3875$)(\mathrm{v} / \mathrm{v})$ of E. camaldulensis Dehn EO. After treatment, the cell viabilities were evaluated using a spot viability plate [14]. For this, the exposed cultures were serially diluted into LB media and $10 \mu \mathrm{L}$ were spotted on LB agar in a Petri dish and incubated for 24 hours at $35^{\circ} \mathrm{C}$. The extent of growth was used as an indication of viability.

Production of PLA film and E. camaldulensis EO-loaded PLA nanofibers

PLA nanofibers and E. camaldulensis EO-loaded PLA nanofibers were produced according to the procedure described by [15-17], with some modifications. E. camaldulensis EO-loaded PLA films were prepared by adding different concentrations $(5 \%, 10 \%$ and $15 \%$ ) of E. camaldulensis EOs to $0.4 \mathrm{~g}$ of PLA dissolved in a mixture of three solvents ( $3 \mathrm{~mL}$ of DCM/1 mL of DMF and $1 \mathrm{~mL}$ of THF) and stirred for 24 hours at room temperature. The final solutions were stirred at room temperature for 30 minutes before electrospinning. The polymer solutions were introduced in a $5 \mathrm{~mL}$ syringe. The injection of this solution was done with a constant flow of $1.5 \mathrm{ml} / \mathrm{h}$. To obtain the electrospinning of the solutions, a voltage of $15 \mathrm{kV}$ and a separation distance of $15 \mathrm{~cm}$ were used. E. camaldulensis EO loaded PLA nanofibers with 7.5\%, 10\% and 15\%, and 50\% were ticketed PLA-EUC-7.5, PLA-EUC-10 and PLA-EUC-15, respectively.

\section{Nanofibers characterization}

The surface morphology of the samples was analyzed using scanning electron microscopy (SEM; JEOL JSM7100-F) with $15 \mathrm{kV}$ working voltage. Fourier transform infrared spectrometer (FT-IR) spectra of PLA control nanofibers and PLA-EUC nanofibers were recorded from wave number $600-4000 \mathrm{~cm}^{-1}$ with a resolution of 2 $\mathrm{cm}^{-1}$, using a Perkin Elmer spectrum. TGA analysis of the samples were carried out with a TGA 8000 Perkin Elmer. The approximately $3 \mathrm{mg}$ samples were tested under a nitrogen atmosphere at a heating rate of $10^{\circ} \mathrm{C} / \mathrm{min}$ with a temperature profile of $30^{\circ} \mathrm{C}$ to $550^{\circ} \mathrm{C}$. Dynamic mechanical analysis of PLA-EUC nanofibers was performed with a DMA 8000 Perkin Elmer. Samples were heated at $30^{\circ} \mathrm{C}$ to $100^{\circ} \mathrm{C}$; tension film geometry was used under frequency 1 $\mathrm{Hz}$ and heating rate $3^{\circ} \mathrm{C} / \mathrm{min}$.

In vitro release studies

In a microtube, $20 \mathrm{mg}$ of PLA-EUC nanofibers were dissolved in $5 \mathrm{~mL}$ of $60 \%$ phosphate buffer saline $(\mathrm{pH}=7.4)+40 \%$ ethanol [18] and incubated at room temperature. At definite time intervals, a specific volume of supernatant was withdrawn for analysis, and was replaced with an equivalent volume of fresh buffer. The amount of released E. camaldulensis EO was measured using UV-Visible spectrophotometer at a wavelength of $222 \mathrm{~nm}$. Cumulative percentage of E. camaldulensis EO released was determined using the following equation:

Cumulative release percentage $=\sum_{\mathrm{t}=0}^{t} \frac{M t}{M 0} \times 100$ (1)

Where:

Mt: Cumulative amount of E. camaldulensis EO released at each sampling point.

M0: The initial weight of the E. camaldulensis EO- loaded in the sample.

\section{Antibacterial activities of EO loaded PLA nanofibers}

The antibacterial activity of the nanofibers was qualitatively tested by the disc diffusion method against Gram (+) strains; S. aureus ATCC 25923 and, E. faecalis ATCC 29212, and Gram (-) strains P. aeruginosa PA01 and, E. coli ATCC 25922. Initially, $100 \mu \mathrm{L}$ of the bacterial suspension ( 0.5 McFarland turbidity) was spread on the Luria Bertani Agar (LBA) plate. And then, the nanofibers (diameter $=15 \mathrm{~mm}$ ) were placed on LBA plate and incubated at $37^{\circ} \mathrm{C}$ for $24 \mathrm{~h}$. Finally, the diameters of inhibition zones around the nanofibers were measured [19].

\section{Anti-Biofilm properties of EO loaded PLA nanofibers}

P. aeruginosa PA01 cells were inoculated into LB medium to an OD600nm of 0.02 . One milliliter of the diluted cultures was mixed with the PLA-EUC nanofibers and incubated at $35^{\circ} \mathrm{C}$. Non adherent cells were removed by washing with distilled water. The biofilms were stained for $10 \mathrm{~min}$ with $0.1 \%$ crystal violet and the cells were washed with distilled water to remove excess dye. For quantification of attached cells, crystal violet was extracted with $95 \%$ etha- 
Fabrication, Characterization, In Vitro Release, and Some Biological Activities of Eucalyptus Essential Oil Loaded Poly (Lactic Acid) Nanofibers

nol, and the absorbance was measured spectrophotometrically at OD570nm [20].

\section{Results and Discussion}

Chemical compounds of E. camaldulensis Dehn. EO

GC-MS analysis of E. camaldulensis Dehn. EO had detected 28 constituents (Table 1). The main components of the EO was pcymene (26.62\%) followed by eucalyptol (19.04\%), spathulenol (13.62\%), cryptone (7.34\%), $\beta$-Phellandrene (5.63\%) and (-)-Terpinèn-4-ol (4.52\%) (Figure 2). The chemical composition of $E$. camaldulensis EO has been studied by other research teams. For example, Dogan., et al. (2017) studied the chemical composition of E. camaldulensis Dehn. EO from different parts of the plant (leaf and fruit) collected from natural habitats in Mersin (Turkey) [21]. They reported that the composition of the EO extracted from eucalyptus leaves was characterized by high proportions of p-Cymene of around $42.1 \%$. While 1, 8-cineol (34.5\%) was the major component of EO extracted from fruits. Sliti., et al. (2010), identified 26 components representing $92.82 \%$ of the total E. camaldulensis oil collected in the Korbos region, including Spathulenol (20.2\%), $\rho$-Cymene (14.83\%), 1,8-cineole ( $12.16 \%$ ) and phellandral (6.6\%) [22]. However, the EO of E. camaldulensis from Malaysia was rich mainly in $\gamma$-terpinene $(71.36 \%)$ then o-cymene $(17.63 \%)$ and terpinen-4-ol (7.01\%) [23]. The EOs of E. camaldulensis originating from Taiwan have two chemotypes: the first is characterized by the predominance of 1,8-cineole (29.6\%) [24], while the second is marked by the co-dominance of $\alpha$-pinene $(22.52 \%)$, p-cymene (21.69\%) and $\alpha$-phellandrene (20.08\%) [25]. The variations in the chemical components of E. camaldulensis Dehn. EOs might be expected to occur according to plant organ, geographical origin, season and extraction procedures [21,26,27].

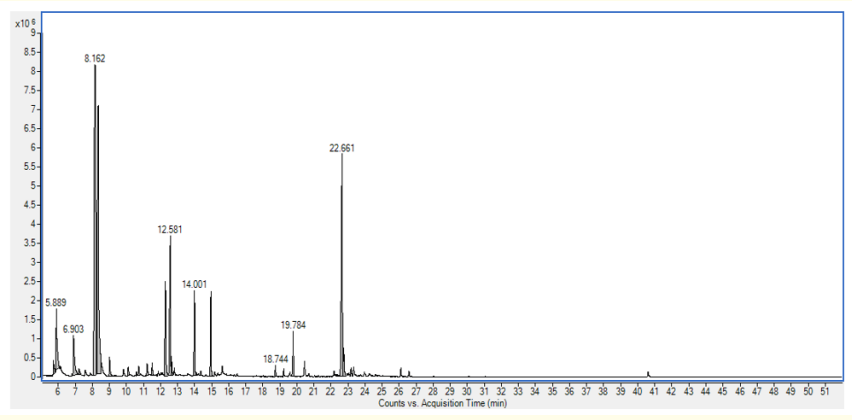

Figure 2: A typical GC/MS chromatogram showing the chemical analysis of EO from fresh aerial part of E. camaldulensis Dehn.

\begin{tabular}{|c|c|c|c|c|}
\hline No & Compounds & $\mathrm{N}^{\circ} \mathrm{CAS}$ & $T_{R}$ & $\%$ \\
\hline 1 & $\alpha$-Thujene & $2867-05-2$ & 5.728 & 0.62 \\
\hline 2 & $\alpha$-pinene & $80-56-8$ & 5.889 & 3.43 \\
\hline 3 & $(-)$ - $\beta$-Pinene & $18172-67-3$ & 6.903 & 2.66 \\
\hline 4 & $\beta$-Myrcene & $123-35-3$ & 7.222 & 0.29 \\
\hline 5 & $\alpha$-Phellandrene & & 7.576 & 0.35 \\
\hline 6 & p-Cymene & $99-87-6$ & 8.162 & 26.62 \\
\hline 7 & 及-Phellandrene & & 8.24 & 5.63 \\
\hline 8 & $\begin{array}{c}\text { 1,8 Cineole/ } \\
\text { Eucalyptol }\end{array}$ & $470-82-6$ & 8.347 & 19.04 \\
\hline 9 & $\mathrm{\gamma}$-Terpinene & $99-85-4$ & 9.011 & 0.95 \\
\hline 10 & Trace & - & 9.83 & 0.41 \\
\hline 11 & Linalool & $78-70-6$ & 10.102 & 0.4 \\
\hline 12 & $\begin{array}{c}\text { 2-Cyclohexen-1-ol, } \\
\text { 1-methyl-4 } \\
\text {-(1-methylethl)- } \\
\text {,trans }\end{array}$ & $29803-81-4$ & 10.72 & 0.43 \\
\hline 13 & 1-Terpineol & $586-82-3$ & 11.213 & 0.62 \\
\hline 14 & 1-Butylcyclohexene & $3282-53-9$ & 11.507 & 0.47 \\
\hline 15 & (-)-Terpinen-4-ol & $20126-76-5$ & 12.29 & 4.52 \\
\hline 16 & Cryptone & $500-02-7$ & 12.581 & 7.34 \\
\hline 17 & $\alpha$-Terpineol & $98-55-5$ & 12.648 & 0.73 \\
\hline 18 & Myrtenal & $564-94-3$ & 12.81 & 0.27 \\
\hline 19 & Cuminaldehyde & $122-03-2$ & 14 & 3.23 \\
\hline 20 & Phellandral & 21391-98-0 & 14.956 & 3.24 \\
\hline 21 & Carvacrol & $499-75-2$ & 15.62 & 0.54 \\
\hline 22 & Caryophyllene & $87-44-5$ & 18.744 & 0.39 \\
\hline 23 & Aromadendrene & $72747-25-2$ & 19.232 & 0.27 \\
\hline 24 & Alloaromadendrene & $25246-27-9$ & 19,784 & 1.68 \\
\hline 25 & Trace & - & 20.452 & 0.62 \\
\hline 26 & Spathulenol & $6750-60-3$ & 22.661 & 13.62 \\
\hline 27 & (+) Spathulenol & $77171-55-2$ & 22.754 & 1.32 \\
\hline 28 & Ledol & $577-27-5$ & 23.186 & 0.3 \\
\hline
\end{tabular}

Table 1: The chemical composition of EO extracted from aerial part of E. camaldulensis Denh. 
Fabrication, Characterization, In Vitro Release, and Some Biological Activities of Eucalyptus Essential Oil Loaded Poly (Lactic Acid) Nanofibers

Study of the antibacterial activity of E. camaldulensis Dehn EO

The antibacterial property of E. camaldulensis Dehn. EO against four different strains, including two Gram-positive ( $S$. aureus, E. faecalis) and two Gram-negative strains (E. coli, P. aeruginosa) was tested using the spot viability assay. This property is shown in table 2 .

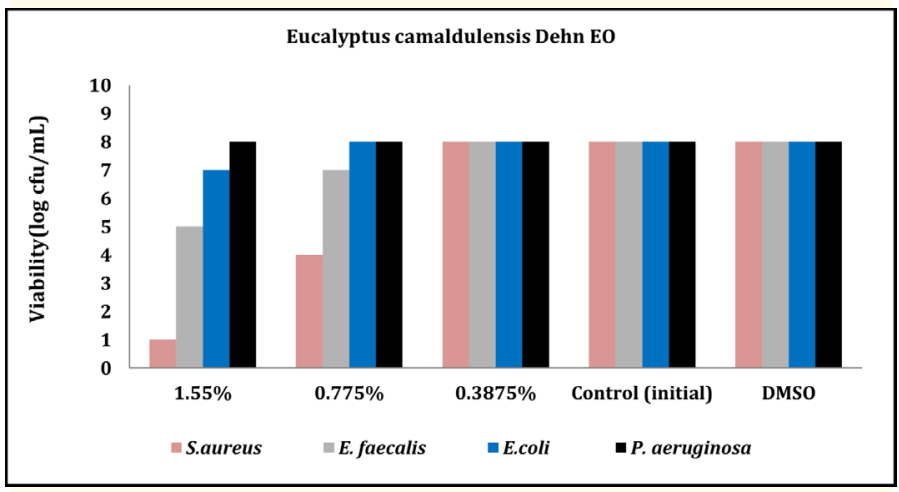

Figure 3: Spot viability assay of the EO of E. camaldulensis.

In the present study E. camaldulensis EO showed a strong antibacterial activity for $S$. aureus (4 log reduction) at a concentration of $0.7 \%(\mathrm{v} / \mathrm{v})$, while a limited antibacterial activity for E. faecalis (1 log reduction) and no antibacterial activity for E. coli and P. aeruginosa.

At a concentration of $1.55 \%$, the E. camaldulensis EO exhibited very strong antibacterial activity for $S$. aureus (7 log reduction) and E. faecalis (3 log reduction), while it demonstrated limited antibacterial activity for $E$. coli (1log reduction). The result demonstrated that E. camaldulensis EO did not show any antibacterial activity against $P$. aeruginosa PA01 for any of the concentrations tested. As far as we know, this is the first report on antibacterial activity of the E. camaldulensis EO for E. faecalis.

Similarly, other previous studies [28-30] had also supported the antibacterial behavior of $E$. camaldulensis EO.

\section{SEM analysis}

The analysis of the structure of EOs loaded nanofibers (10\%) was carried out by SEM. The working voltage is $15 \mathrm{kV}$.

\begin{tabular}{|l|c|c|c|c|}
\hline E. camaldulensis & \multicolumn{5}{|c|}{ Viability cfu/mL } \\
\hline & S. aureus & E. faecalis & E.coli & P. aeruginosa \\
\hline $1.55 \%$ & 1 & 5 & 7 & 8 \\
\hline $0.775 \%$ & 4 & 7 & 8 & 8 \\
\hline $0.3875 \%$ & 8 & 8 & 8 & 8 \\
\hline Control (initial) & 8 & 8 & 8 & 8 \\
\hline DMSO & 8 & 8 & 8 & 8 \\
\hline
\end{tabular}

Table 2

In this case, the polymer polylactic acid (PLA) was used to prepare nanofibers. Using SEM observations, an examination, of the modifications in the morphology of PLA films, is performed after including antibacterial agents. Usually, the surface morphology of a neat PLA is smooth and homogeneous and does not contain any pores and cracks [31].

SEM images of PLA pure and PLA-EUC nanofibers as depicted in figure 4. As can be seen in figure 4, G and I, diameters of PLA-EUC nanofiber were between $116-387 \mathrm{~nm}$. According the table 3 , the average diameter of the neat PLA was $607 \pm 197$ and PLA-EUC was $377 \pm 194$. From these results, the diameters of neat PLA are larger than the EO loaded PLA [32].

\begin{tabular}{|l|c|}
\hline Essential Oils Loaded Nanofibers & Diameters (nm) \\
\hline Neat PLA & $607 \pm 197$ \\
\hline PLA-EUC & $377 \pm 194$ \\
\hline
\end{tabular}

Table 3: The average diameters of the PLA-EUC nanofibers and neat PLA nanofiber.

FT-IR

According the FT-IR spectra of PLA nanofiber (Figure 5), the peaks at $2990 \mathrm{~cm}^{-1}$ and $2940 \mathrm{~cm}^{-1}$ were attributed to $-\mathrm{CH}$ - stretching, the peak at $1760 \mathrm{~cm}^{-1}$ was assigned to $\mathrm{C}=0$ carbonyl group, the peaks at $1180 \mathrm{~cm}^{-1}$ and $1080 \mathrm{~cm}^{-1}$ were belong to $-\mathrm{C}-0$ - stretching and the peak at $860 \mathrm{~cm}^{-1}$ ascribed to -C-COO stretching [33].

The figure 5 shows the FTIR spectrum of PLA-EUC. It is characterized by the presence of the functional groups' characteristic of this type of nanofiber. We note indeed the appearance of a new absorption around $3460 \mathrm{~cm}^{-1}$ attributable to the vibrator $\mathrm{OH}$. This spectrum shows the existence of the absorption bands attributed 

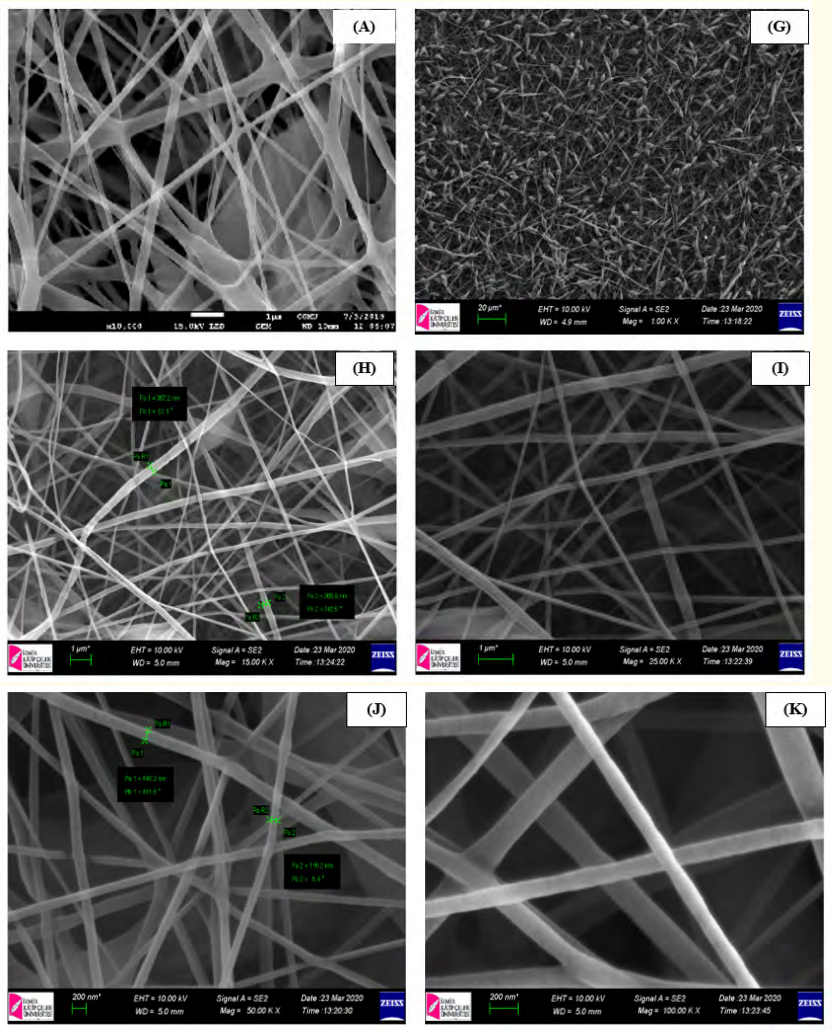

Figure 4: SEM images of the nanofibers. A. Neat PLA., G, H, I, J, K. PLA-EUC nanofibers.

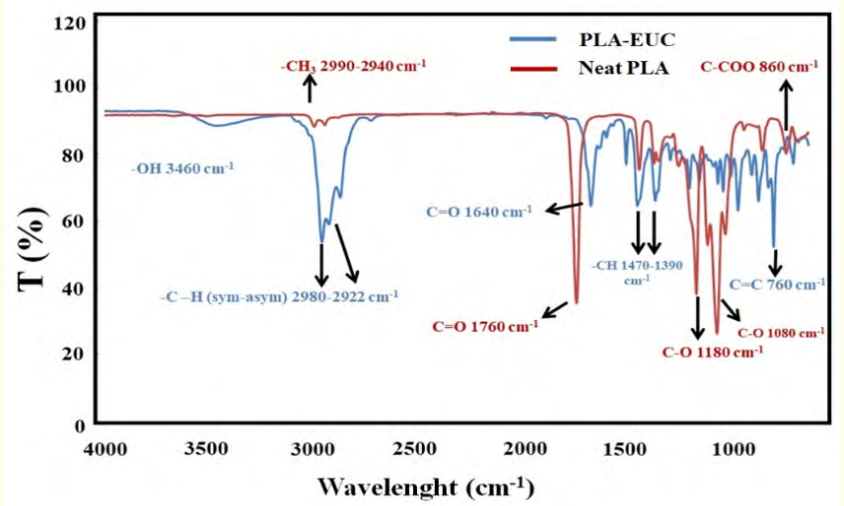

Figure 5: FT-IR Spectrum of neat PLA and PLA-EUC nanofibers. to the two vibration modes of valence symmetrical around 2980 $\mathrm{cm}^{-1}$ and asymmetrical around $2922 \mathrm{~cm}^{-1}$ of the $\mathrm{CH}_{3}$ motif. We also note the appearance of a new characteristic band of amide I group in $1681 \mathrm{~cm}^{-1}$. The bending vibration in $1460 \mathrm{~cm}^{-1}$ and $1380 \mathrm{~cm}^{-1}$ was clearly come up [34]. The existence of the peak at $760 \mathrm{~cm}^{-1}$ was assigned to $\mathrm{C}=\mathrm{C}$ alkene. The appearance of a new band characteristic of a band relating to alkene $\mathrm{C}=\mathrm{C}$ around $760 \mathrm{~cm}^{-1}$.

Thermal properties of PLA-EUC (\%15) nanofibers

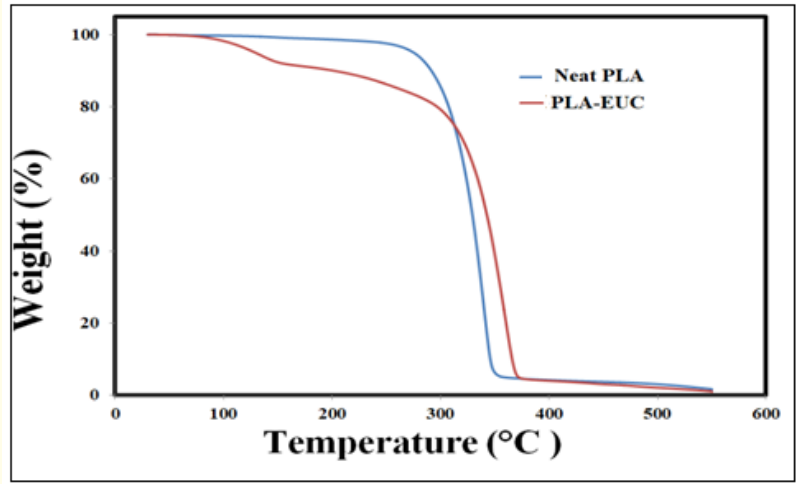

Figure 6: TGA curves of neat PLA and PLA-EUC (\%15) nanofibers.

According to figure 6, PLA showed single-step process decomposition. The polymer matrix contains $15 \%$ Eucalyptus camaldulensis EO resulted in a two-step degradation process, where the first degradation step, between $80-180^{\circ} \mathrm{C}$, corresponds to the degradation or vaporization of certain compounds molecular weight present in the polymer as reported by Muller., et al. (2017) [35]. While the second step is around $300^{\circ} \mathrm{C}$ which corresponds to the degradation of the PLA polymer as reported by Martino., et al. (2006) [36]. Thermal stability of PLA matrixes decreased with adding essential oils in polymer matrix [37].

DMA

The addition of plasticizers leads to decrease of $\mathrm{Tg}$ and the increase of the elasticity [37]. As could be seen from figure 7, EO containing nanofiber mats exhibited a lower Tg for both samples. The $\mathrm{Tg}$ value PLA nanofiber is $53.74^{\circ} \mathrm{C}$, for Eucalyptus containing $(15 \%$ percent) nanofiber mat is $42.28^{\circ} \mathrm{C}$. The changing range of $\mathrm{Tg}$ for 
PLA matrixes have been reported between 17 and $35^{\circ} \mathrm{C}$ with low molecular weight molecules, such as citrates, terpenes, and oil [3840]. Fillers act as a plasticizers, polymer chain mobility and polymer free volume increase and, these resulted the decreasing of $\mathrm{Tg}$ of $[38,41,42]$.
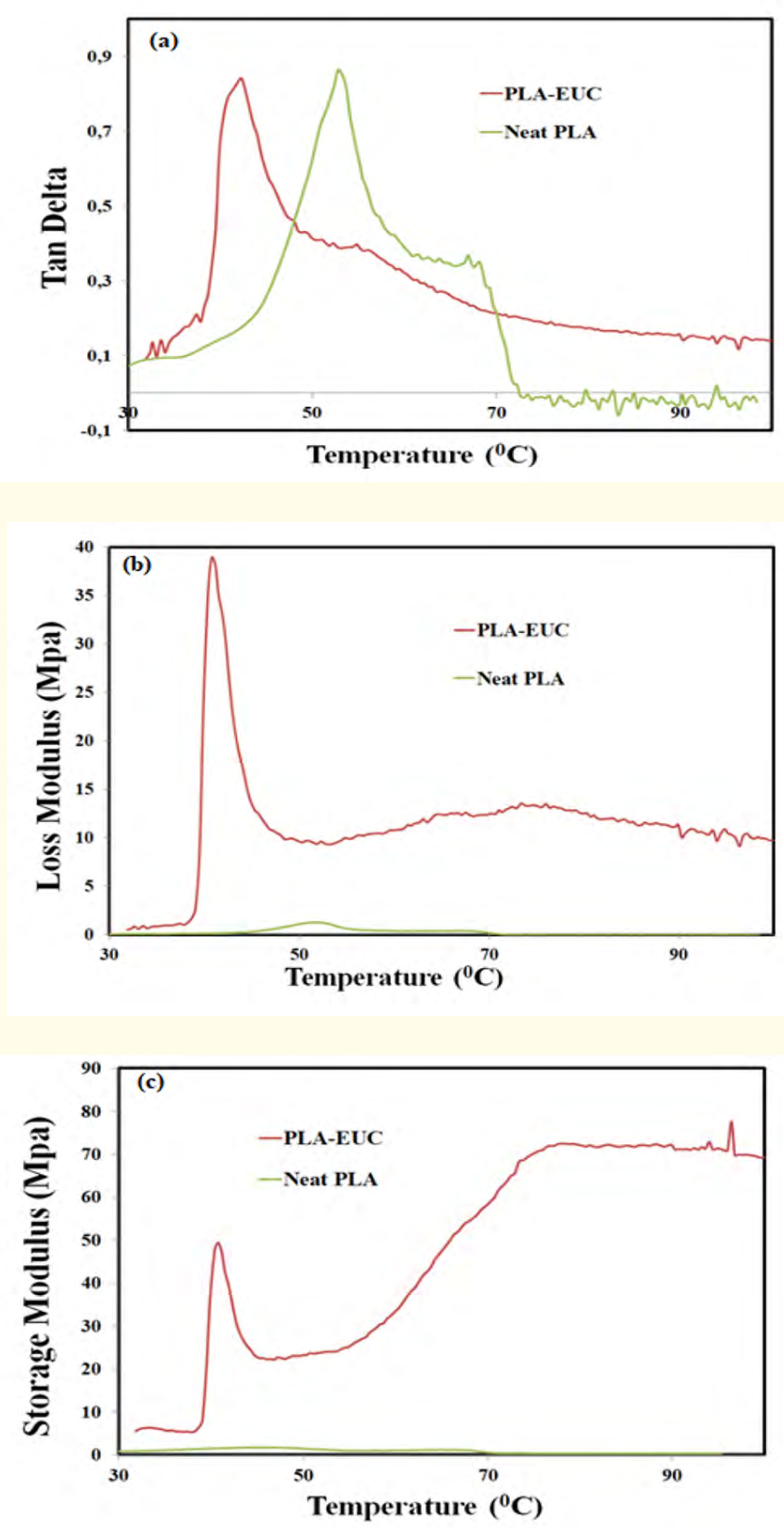

Figure 7: (a) Tan Delta, (b) loss, (c) Storage of the neat PLA and PLA-EUC (\%15) nanofibers.
It can be also seen that the elasticity of PLA nanofiber mats increased by adding EOs. The EOs behave as a plasticizer and, this resulted to increasing of free volume, decreasing of interactions between the polymer chains. These changing's lead to improving the chain mobility and flexibility [42]. Zhang., et al. (2017) [40] reported that the EOs work as plasticizers for PLA, lowering the glass transition temperature of the resulting composite fibers up to $60 \%$ and increasing elongation-at-break and tensile strength up to 12 times.

\section{Release profile}

Release behavior of PLA-EUC nanofibers was shown in figure 8. The PLA-EUC nanofibers were released about 160h. In 6 hours burst release were observed for PLA-EUC. According the results lowest percentage of EO (7.5\%) in nanofibers was showed the best releasing behavior and the amount of the releasing decreased as the rate increased. In $10 \%$ of PLA-EUC nanofibers were released about 70 percent and nearly 50 percent were released from $15 \%$ of PLA-EUC [43].

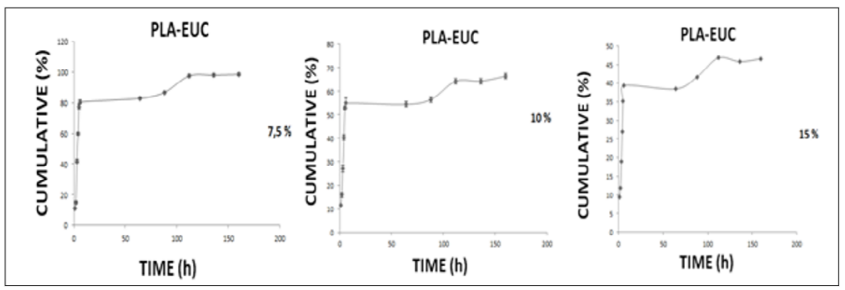

Figure 8: Releasing behavior of the PLA-EUC nanofibers.

The antibacterial activity of nanofibers

The antibacterial property of E. camaldulensis EO loaded PLA nanofibers at different concentrations (7.5, 10 and 15\%), against the $S$. aureus and E. coli was tested using the agar diffusion method. E. camaldulensis EO loaded nanofibers do not show such behavior (Table 4).

\section{Study of the anti-Biofilm Activity of E. camaldulensis EO loaded} PLA nanofiber

The biofilm production was determined in the presence of varying amounts of Eucalyptus camaldulensis EO (ranging from 2.5 to $0.15625 \%$ ) against $P$. aeruginosa PA01, significant inhibition of biofilm formation was not observed. 
Fabrication, Characterization, In Vitro Release, and Some Biological Activities of Eucalyptus Essential Oil Loaded Poly (Lactic Acid)

\begin{tabular}{|l|c|c|}
\hline & \multicolumn{2}{|c|}{$\begin{array}{r}\text { Inhibition zon diameters } \\
\text { (mm) }\end{array}$} \\
\hline \multicolumn{1}{|c|}{ (Nanofibers $\mathbf{1} \mathbf{~ c m}^{\mathbf{2}}$ ) } & S. aureus & E. coli \\
\hline E. camaldulensis $7.5 \%$ & $*$ & $*$ \\
\hline E. camaldulensis $10 \%$ & $*$ & $*$ \\
\hline E. camaldulensis $15 \%$ & $*$ & $*$ \\
\hline Kanamisin & $10 \pm 1.1$ & $11 \pm 1.1$ \\
\hline *: No Inhibition & & \\
\hline
\end{tabular}

Table 4: The antibacterial activity of E. camaldulensis EO loaded PLA nanofiber.

After $24 \mathrm{~h}$ in the presence of E. camaldulensis EO loaded PLA nanofiber samples, biofilm formation of P. aeruginosa PA01 decreased with approximately 9.3\%, 12.8\% and 12.6\% (Figure 9), compared to biofilm formation in the absence of nanofibers.

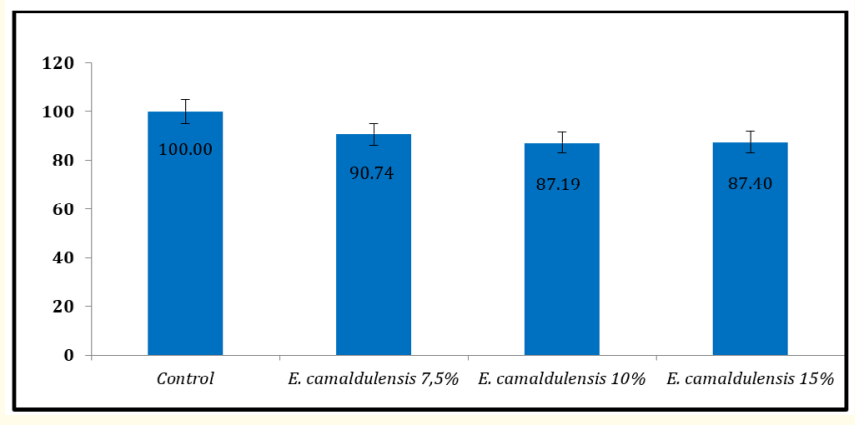

Figure 9: Anti-biofilm activity of Eucalyptus camaldulensis Dehn. EO loaded PLA nanofibers against P. aeruginosa.

\section{Conclusion}

Chemical analysis of E. camaldulensis EO by GC-MS reveals its richness in p-cymene (26.62\%) followed by eucalyptol (19.04\%), spathulenol (13.62\%) and cryptone (7.34\%). The E. camaldulensis EO exhibited significant antibacterial activity against $S$. aureus and E. faecalis. This antibacterial activity could be attributed to pcymene, eucalyptol and spathulenol. Two-step decomposition process was observed for EO containing PLA matrixes and the decreasing on thermal stability of the matrixes was observed by adding EOs. The adding of EOs in polymer matrixes was resulted the decreasing of $\mathrm{Tg}$ and increasing on elasticity of final matrixes.
In our case, it can be revealed that E. camaldulensis Dehn. EOs can serve as bio plasticizers when they are incorporated into the PLA matrix.

\section{Acknowledgements}

This research work was carried out in the science and technology laboratory at Çanakkale Onsekiz Mart University under the scientific direction of Professor Ayhan Oral. I take this opportunity to express my sincere gratitude to him for the confidence he has placed in me to carry out this project in his laboratory. Finally, I would like to take this opportunity to thank Mr. Mohsen Dkhil.

\section{Bibliography}

1. Greiner A and Wendorff JH. "Cover Picture: Electrospinning: A Fascinating Method for the Preparation of Ultrathin Fibers (Angew. Chem. Int. Ed. 30/2007)". Angewandte Chemie International Edition 46.30 (2007): 5633-5633.

2. Dzenis Y. "Spinning Continuous Fibers for Nanotechnology". Science 304. 5679 (2004): 1917-1919.

3. Li D., et al. "Electrospinning: A Simple and Versatile Technique for Producing Ceramic Nanofibers and Nanotubes". Journal of the American Ceramic Society 89.6 (2006): 1861-1869.

4. Frenot A and Chronakis IS. "Polymer Nanofibers Assembled by Electrospinning". Current Opinion in Colloid nad Interface Science 8.1 (2003): 64-75.

5. Ahn Y., et al. "Development of High Efficiency Nanofilters Made of Nanofibers". Current Applied Physics 6.6 (2006): 1030-1035.

6. Reyes-Jurado F., et al. "Essential Oils: Antimicrobial Activities, Extraction Methods, and Their Modeling". Food Engineering Reviews 7.3 (2015): 275-297.

7. López P., et al. "Development of Flexible Antimicrobial Films Using Essential Oils as Active Agents". Journal of Agricultural and Food Chemistry 55.21 (2007): 8814-8824.

8. Qin Y., et al. "Development of Active Packaging Film Made from Poly (Lactic Acid) Incorporated Essential Oil". Progress in Organic Coatings 103 (2017): 76-82.

9. Wang H., et al. "Diffusion and Antibacterial Properties of NisinLoaded Chitosan/Poly (L-Lactic Acid) Towards Development 
of Active Food Packaging Film". Food and Bioprocess Technology 8.8 (2015): 1657-1667.

10. Tsuji H. "Poly (Lactic Acid): Synthesis, Structures, Properties, Processing, and Applications". Wiley (2011).

11. Ghalem BR and Mohamed B. "Antibacterial Activity of Leaf Essential Oils of Eucalyptus Globulus and Eucalyptus Camaldulensis". African Journal of Pharmacy and Pharmacology 2.10 (2008): 211-215.

12. Khalaf ZZ and Zahra LA. "Evaluation of the Activity of Essential Oil and Hydrosol from Eucalyptus Camaldulensis against Some Bacterial Species". Iraqi Journal of Science (2020): 1282-1288.

13. Pharmacopée Européenne. Strasbourg Conseil De L'europe. Ed. edition, 4éme (2002).

14. Im H., et al. "Combined Application of Bacterial Predation and Violacein to Kill Polymicrobial Pathogenic Communities". Scientific Reports 7.1 (2017): 1-10.

15. Angeles M., et al. "Emulsion Electrospinning: Composite Fibers from Drop Breakup During Electrospinning". Polymers for Advanced Technologies 19.7 (2008): 728-33.

16. Rieger KA and Schiffman JD. "Electrospinning an Essential Oil: Cinnamaldehyde Enhances the Antimicrobial Efficacy of Chitosan/Poly (Ethylene Oxide) Nanofibers". Carbohydrate Polymers 113 (2014): 561-568.

17. de Oliveira Mori CL., et al. "Electrospinning of Zein/Tannin BioNanofibers". Industrial Crops and Products 52 (2014): 298-304.

18. Hosseini SF., et al. "Two-Step Method for Encapsulation of Oregano Essential Oil in Chitosan Nanoparticles: Preparation, Characterization and in Vitro Release Study". Carbohydrate Polymers 95.1 (2013): 50-56.

19. Hufford C., et al. "Two Antimicrobial Alkaloids from Heartwood of Liriodendron Tulipifera L". Journal of Pharmaceutical Sciences 64.5 (1975): 789-792.

20. Truchado P., et al. "Inhibition by Chestnut Honey of N-AcylL-Homoserine Lactones and Biofilm Formation in Erwinia Carotovora, Yersinia Enterocolitica, and Aeromonas Hydrophila". Journal of Agricultural and Food Chemistry 57.23 (2009): 11186-11193.
21. Dogan G., et al. "Chemical Composition and Biological Activities of Leaf and Fruit Essential Oils from Eucalyptus Camaldulensis". Zeitschrift für Naturforschung C 72.11-12 (2017): 483-489.

22. Sliti S., et al. "Leaf Essential Oils Chemical Composition, Antibacterial and Antioxidant Activities of Eucalyptus Camaldulensis and E. Rudis from Korbous (Tunisia)". Journal of Materials and Environmental Science 6.3 (2015): 743-748.

23. Mubarak EE., et al. "Essential Oil Compositions from Leaves of Eucalyptus Camaldulensis Dehn. And Callistemon Viminalis Originated from Malaysia". IPCBEE 70 (2014): 137-141.

24. Su Y-C., et al. "Antifungal Activities and Chemical Compositions of Essential Oils from Leaves of Four Eucalypts". Taiwan Journal of Forest Science 21.1 (2006): 49-61.

25. Cheng S-S., et al. "Chemical Compositions and Larvicidal Activities of Leaf Essential Oils from Two Eucalyptus Species". Bioresource Technology 100.1 (2009): 452-456.

26. Knezevic P., et al. "Antimicrobial Activity of Eucalyptus Camaldulensis Essential Oils and Their Interactions with Conventional Antimicrobial Agents against Multi-Drug Resistant Acinetobacter Baumannii". Journal of Ethnopharmacology 178 (2016): 125-136.

27. Ostad Asiaei E., et al. "Evaluation of Antimicrobial Activity of Eucalyptus Camaldulensis Essential Oil against the Growth of Drug-Resistant Bacteria". Jundishapur Journal of Natural Pharmaceutical Products 13.4 (2018).

28. Singh R and Thakur R. "Antibacterial Activity of Eucalyptus Camaldulensis against Bacteria Causing Food-Borne Illness". The Indian Medical Gazette (2016): 195-99.

29. Alghamdi AI and Ababutain IM. "Research Article Phytochemical Screening and Antibacterial Activity of Eucalyptus Camaldulensis's Leaves and Bark Extracts" (2019).

30. Traore N., et al. "Antimicrobial Activity of Essential Oils of Eucalyptus Camaldulensis from Mali". Asian Journal of Plant Science and Research 4.4 (2014): 69-73.

31. Javidi Z., et al. "Development of Flexible Bactericidal Films Based on Poly (Lactic Acid) and Essential Oil and Its Effectiveness to Reduce Microbial Growth of Refrigerated Rainbow Trout”. LWT-Food Science and Technology 72 (2016): 251-260. 
32. Pankongadisak P., et al. "The Use of Electrospun CurcuminLoaded Poly (L-Lactic Acid) Fiber Mats as Wound Dressing Materials". Journal of Drug Delivery Science and Technology 53 (2019): 101121.

33. Kister G., et al. "Effects of Morphology, Conformation and Configuration on the Ir and Raman Spectra of Various Poly (Lactic Acid) S”. Polymer 39. 2 (1998): 267-273.

34. Inceboz T., et al. "In-Vivo and in-Vitro Tick Repellent Properties of Cotton Fabric”. Textile Research Journal 85.19 (2015): 20712082.

35. Muller J., et al. "Poly (Lactic) Acid (Pla) and Starch Bilayer Films, Containing Cinnamaldehyde, Obtained by Compression Moulding”. European Polymer Journal 95 (2017): 56-70.

36. Martino V., et al. "Thermal and Mechanical Characterization of Plasticized Poly (L-Lactide-Co-D, L-Lactide) Films for Food Packaging". Journal of Thermal Analysis and Calorimetry 86.3 (2006): 707-712.

37. Tawakkal IS., et al. "A Review of Poly (Lactic Acid)-Based Materials for Antimicrobial Packaging". Journal of Food Science 79. 8 (2014): R1477-1490.

38. Mekonnen T., et al. "Progress in Bio-Based Plastics and Plasticizing Modifications". Journal of Materials Chemistry A 1.43 (2013): 13379-98.

39. Arrieta MP., et al. "Characterization of Pla-Limonene Blends for Food Packaging Applications". Polymer Testing 32. 4 (2013): 760-768.

40. Zhang W., et al. "Electrospinning of Polylactic Acid Fibres Containing Tea Tree and Manuka Oil". Reactive and Functional Polymers 117 (2017): 106-111.

41. Nagarajan V., et al. "Perspective on Polylactic Acid (Pla) Based Sustainable Materials for Durable Applications: Focus on Toughness and Heat Resistance". ACS Sustainable Chemistry and Engineering 4.6 (2016): 2899-2916.

42. Vieira MGA., et al. "Natural-Based Plasticizers and Biopolymer Films: A Review”. European Polymer Journal 47.3 (2011): 254263.
43. Liu Y., et al. "Fabrication of Electrospun Polylactic Acid/ Cinnamaldehyde/B-Cyclodextrin Fibers as an Antimicrobial Wound Dressing". Polymers 9.10 (2017): 464.

\section{Assets from publication with us}

- Prompt Acknowledgement after receiving the article

- Thorough Double blinded peer review

- Rapid Publication

- Issue of Publication Certificate

- High visibility of your Published work

Website: www.actascientific.com/

Submit Article: www.actascientific.com/submission.php

Email us: editor@actascientific.com

Contact us: +919182824667 